\title{
Social Risks of Medical Tourism
}

\author{
Gennady Yurievich Shchekin ${ }^{1} \&$ Tatiana Ivanovna Guba ${ }^{1}$ \\ ${ }^{1}$ State Government-Funded Educational Institution of Higher Professional Training under the Ministry of Health \\ of the Russian Federation "Volgograd State Medical University", Russia \\ 1, Pavshikh Bortsov Sq., Volgograd 400131, Russia \\ Correspondence: Gennady Yurievich Shchekin, State Government-Funded Educational Institution of Higher \\ Professional Training under the Ministry of Health of the Russian Federation "Volgograd State Medical \\ University", 1, Pavshikh Bortsov Sq., Volgograd 400131, Russia.
}

Received: November 1, 2014 Accepted: December 23, 2014 Online Published: March 16, 2015

doi:10.5539/ass.v11n7p233 URL: http://dx.doi.org/10.5539/ass.v11n7p233

\begin{abstract}
Modern medicine as a subject of international tourism. Conceptual approaches to the definition and description of medical tourism were analyzed. International experience in rendering services of medical tourism, its rapid growth in such countries as the USA, Germany Israel and India was studied. A range of serviced rendered by foreign medical institutions was described. Prospects of medical tourism in today's Russia was considered. Social role of travel agencies in development of medical tourism was described. Social risks were revealed and described and recommendations to develop medical tourism were suggested.
\end{abstract}

Keywords: medical tourism, socially significant diseases, social agents of medical tourism

\section{Introduction}

Modern medicine plays an important role in international tourism industry. The concept of "medical tourism" describes a rapidly growing phenomenon where people go abroad, not only for sightseeing, but also to solve health problems. Medical tourism is an integral part of domestic and international tourism market. The term "medical tourism" originated in the 80 s of the last century, but today it has become a huge market, representing a promising direction for business (Tourists go for medical treatment, 2011). The global market for medical tourism is now estimated at $\$ 100$ billion per year. The origin of this phenomenon was caused by: integration of European countries; simplification of tourists migration. appearance of the international tourism market, creation of high-tech biomedical and health care organizations; changes in national and international legislation in the field of medicine in accordance with the principle of respect for a patient, creation of the global information space (the Internet), and fundamentally new means of communication, spread of high-speed transport. Another reason for the spread of this phenomenon was increase in health care costs, which has been noted recently. Nowadays a global market for medical services with its own infrastructure (health management, accrediting bodies, agencies, medical tourism and travel agencies) has been established. Increase in health care costs is expected to be $6 \%$ per year, which will lead to less expenditures. Taking into account that medical tourism allows to save up to $70 \%$ of costs in the patient's country, growth of this sector of economy is expected to reach $35 \%$ per year (Medical tourism is beneficial to everybody, 2011).

The term "medical tourism" often means organization of medical services rendered to patients outside their own country. Moreover, in the context of economical activity such medcal care should be permanent, foreign citizens being the main consumers (Medical tourism, n. d.).

In a broad sense, medical tourism can be defined as a field of medical industry and hospitality integrating markets into a single system with a developed infrastructure, including not only health facilities, but also a variety of business sectors - insurance, banking, legal assistance, transportation and communication. Medical tourism in the broadest sense also includes migration of not only patients but also medical staff, diagnostic and surgical equipment. This area is not sufficiently developed so far, nevertheless the prospects are clear (Shchekin \& Antonova, 2013). 


\section{Methods}

The article was written in the research field of sociology of medicine, which made it possible to use methodology of sociology of medicine to make research into medical tourism. Having applied conventional methods of sociology, such as content-analysis, questioning, case-study and focus-group, the authors made an attempt to reveal .foreground trends of medical tourism development illustrated by the example of some European countries, the USA, India and Russia. As well as to specify social risks of medical tourism within the frames of rendering medical aid to international patients.

\section{Results}

Medical tourism is very popular in developed countries. The current level of advanced medical technology in such countries as Germany, the United States, Britain, Israel, Switzerland makes these countries the leaders of the up-to-date treatment. Medical care in these countries is based on an accurate diagnosis using revolutionary methods and the latest medical equipment, new surgical methods and unique rehabilitation programs. US medicine is leading in transplantology. In particular it concerns most complicated surgeries, such as heart and lung transplantation. The second place belongs to treatment of oncological diseases. Then come cardiology, orthopedics and neurosurgery. Health care in the USA is the world's leader in respect of medical resources and financing. The amount of health care workers is over 10 million people and USA is on the first place by financing of healthcare (Health care in the USA, 2014). Besides, the USA take the first place in the both in the level and results of medical researches which makes it possible to provide the national health care system with most up-to-date medical equipment, medicines and disposable materials. President Barak Obama's Administration has not only retained priority in budget financing medical research programs but also increased it significantly (Lebedeva, 2011).

While undergoing medical treatment in the USA hospitals, patients can be sure that they won't get any secondary diseases, infections or complications, as American health care workers pay particular attention to prevention of different diseases. The most famous medical clinics attracting the utmost number of patients, including those from abroad, are: John Hopkins Hospital (Baltimore), Ronald Reagan Medical Center ( Los Angeles), Mayo Clinic ( Rochester, MN), General hospital in Massachusetts (Boston), New York Presbyterian University Hospital of Columbia and Cornell, the Medical Center of San Francisco, Hospital of the University of Pennsylvania (Philadelphia), etc. At the same time, medical services in the U.S, being the best in the world, are also the most expensive. The reason for this is a very expensive health care system, which includes high doctors' fees, high-tech methods of examination and treatment, drugs of the last generation.

Germany is one of the centers of advanced medical science, where treatment is most effective. Its cost is less than, for example, in Switzerland or in the United Kingdom, but the quality is not worse than in the above countries. Peculiarity of health care in Germany is that hospitals are equipped with latest medical apparatuses and devices, application of up-to-date research results, high skills of doctors and nurses (Medical treatment in Germany). Today such specialties as ophthalmology, gynecology, neurosurgery, cardiology, orthopedics and urology enjoy popularity among patients undergoing treatment in Germany. Strokes, tumors of the brain and spinal cord, tumors of the gastrointestinal tract, treatment of leukemia, etc., are carried out under special programs. Such public clinics in Germany as Bochum University Medical Center, University Medical Center in Duesseldorf, Cologne University Medical Center, Muenster University Hospital, Essen University Hospital, as well as specialized clinics, such as the Academic Hospital Bethesda (Moenchengladbach), Gamma- Knife Center (Krefeld), Evangelical Hospital (Duesseldorf), Preventikum Clinic (Essen, etc., as well as private clinics, for example, Dr. Gaysenhofer's Gynecological Clinic (Munich) or Dr. D. Baumgart's private cardiological clinic (Duesseldorf), Doctor Sallfeld's Private Phlebological Clinic" Artemed" (Bad Oeynhausen).

No less popular country in the field of medical tourism is Israel, whose high level of medicine is well known worldwide. Medical tourism in Israel is an integrated service, including examination, diagnosis, treatment, accommodation of the patient in the clinic (Electronic European encyclopedia. The state of Israel. Health care system). In their clinics Israeli specialists successfully treat cardiovascular diseases, oncology, leukemia, diseases of the digestive and endocrine system, brain, kidneys, bones, joints. Israeli transplantation and plastic surgery doing wonders are famous worldwide. Israel is a small country but on its territory there are over 250 hospitals, multiprofile health care centers, including hospitals for treatment of chronic diseases, rehabilitation centers and specialized military hospitals (Medical information net).

Friendly atmosphere and professionalism of medical personnel favors development of medical tourism in this country. Obtained data evidence that approximately $65 \%$ of international patients arrive in Israel with rather serious health problems, including oncology, infertility, sports injuries, as well as to undergo cardiological 
surgeries or for bone marrow transplantationa and surgeries on the spinal column, etc. Other $35 \%$ of international tourists go to Israel to undergo plastic surgeries and complex cosmetological procedures. Treatment of foreign tourists is mainly provided by hospitals belonging to the medical organization called "Hadassah" (Jerusalem), Sheba Medical Center Tel- Ha Shoher (Ranat Gan) and the Sourasky Medical Center at Ichilov Hospital (Tel Aviv) which are centers of medical tourism.

One more country of medical tourism that has won popularity is India. This country is ideal for medical tourism due to an upscale health care, medical equipment, individual approach to the patient and most importantly, absence of waiting-lists for operations. One of the factors that attract medical tourists to India is affordability of health services as the cost of care in this country is almost 30\% lower than in Western countries (e.g. heart surgery costs $\$ 80000-120000$ in the United States, is $\$ 900$ in India, coronary artery bypass surgery in the U.S costs $\$ 13000$, and in India - \$2 000). Due to moderate pricing, the flow of patients to India increases, which brought 50 - 100 billion Rupees (\$1.1-1.2 billion) to the country's economy in 2012 (Medical tourism. Made in India). For this reason, issue of medical visas became the priority for the Indian government. To attract medical tourists to the country, specialized travel agencies rendering services exceptionally to medical tourists, were established in India. These agencies provide all necessary medical information to choose and appropriate medical institution for treatment, accommodation and arrival at the hospital, as well as organizing tours about the country before and after treatment. Moreover, a great deal is being done to improve infrastructure of airports and accessibility of services rendered to patients. The number of states engaged in updating medical equipment to attract more patients is increasing.

Both private and public clinics of India provide medical care for a broad scope of patients. The main clinics include the largest network of "Apollo Hospital Group" private clinics located in Bangalore, Chennai, Hyderabad, Delhi, Punjab and Kolkata; Vokhardt clinics having two medical centers, one located in Bangalore and another in Mumbai; Asian Cardiological Institute, located in Mumbai and others. Patients from various developing and developed countries arrive at these clinics for general and special medical treatment, including vascular surgery, bone marrow transplantation, cosmetic surgery, cardiology and heart surgery, dialysis and kidney transplantation, total joint replacement, obstetrics and gynecology, neurosurgery and brain surgery to treat brain cancer - glioblastoma multiforme, orthopedics and treatment of injuries (ASPECT).

Italian health care system corresponds to high European standards and it allows the World Health Organization to recognize Italy the second in the world for accessibility and efficiency of medical aid in 2000 (Treatment in Italy). It happened in spite of the fact that medical tourism and treatment in Italy do not belong to the prior economical trends of the country. Most common reasons for medical tourism in Italy are oncological and children's diseases. When analyzing differences between private and public hospitals, it should be stated that the standard of medical services is mainly the same but private clinics are more comfortable and, as a rule, they provide more confidentiality. Patients who afford a private clinic, can expect services as in a five-star hotel.

The most popular Italian hospitals are: Vehbi Koch Foundation clinic, specializing in oncology and rehabilitation, R.I.D. Cmenta dental clinic, Villa Stuart Sport clinic, specializing in orthopedics, diagnosis of sports injuries and sports medicine. All above mentioned hospitals and clinics provide highly professional medical services. In Rome the patient can apply to the International Our Savior's hospital or to American hospital, or American International Center in Milan.

However, according to a survey by a tourist e-magazine Hotel Resort Insider the list of countries leading in rendering health services, is headed by Panama, Brazil, Malaysia, Costa Rica (Medical tourism: where can you go? 2010). Panama, ranking the first, provides a relatively inexpensive medical care. Operations in Panama are much more affordable than in the U.S., being 40 - 70\% cheaper. Brazil ranks the second, which recently has become a popular destination for cosmetic surgery. The third country is Malaysia, whose medical industry has made a significant leap in its development during the last decade. The range of medical services in the country is quite wide and includes, for example cosmetic surgery, cardiovascular surgery and dental care. The fourth place belongs to Costa Rica. It has become a widely recognized center providing high quality medical services for patients primarily from North America. The key to success in these countries - high quality medical services at affordable prices.

For successful growth and development of medical tourism in patient's interest and his awareness of possibilities to obtain high quality medical care in various countries around the world, a number of associations directly or indirectly affecting these sectors, were established. These associations include: European Medical Tourism Alliance, International Medical Travel Association, Medical Tourism Association, International Association for Medical Assistance to Travellers. The objectives of these associations are creating the largest and most 
comprehensive database in medical tourism, contributing to global integration of health care systems of different countries, councelling and providing information to travelers about the possible health hazards and epidemiological situation in different countries, rendering insurance services. Another aim and objective of these alliances is lobbying bills aimed at improving health care. For example, to successfully promote their services to the market of medical tourism and to help the Indian government a non-profit organization Indian Medical Travel Association (IMTA) was created, whose goal is coordination of marketing activity of medical providers under conditions of strong competitiveness on the world market of medical tourism. IMTA members are leading hospitals, medical centers, agencies, insurance companies and many other institutions dealing with medical tourism, which makes it possible to successfully promote interests of Indian health care to the international level (Traveling to India. Medical tourism).

American Medical Association created a list of medical tourism principles to be followed by all participants of this market. These principles should stimulate further development of the sector under consideration. The following principles are mentioned in the brochure for the patients travelling abroad for medical assistance:

- Medical service rendered abroad should be exclusively voluntary;

- Economic benefits of getting medical services abroad should not infringe upon patient's needs in diagnostics and medical treatment;

- Medical services abroad should be rendered exclusively by medical institutions accredited by corresponding international regulating bodies;

- Medical services rendered by local medical institutions should be properly coordinated and financed to provide regular medical treatment;

- Insurance contract for travelling abroad to get medical treatment should stipulate expenses on medical care after arrival in the home country;

- Patients should be informed about their rights and mechanisms of legal defense before they leave the home country for medical treatment abroad;

- Patients should have a possibility to familiarize themselves with doctors' licenses and accreditations of medical institutions, as well as access to the results of medical examination and diagnostics;

- Patient's medical papers should be transferred according to the principles of Medical Insurance Act;

- Patients should be informed about potential risks of a surgical intervention, as well as long flights and physical activity following it (Medical tourism is beneficial to everybody, 2011).

Development of medical tourism abroad is supported by many travel agencies that organize medical services, which greatly facilitates access to foreign medical institutions to patients. Many hospitals have employees on the staff who speak several languages, which helps do without an interpreter. Along with the traditional tourist issues, such as transportation to the place of treatment, providing comfort and security, agencies choose specialized clinics, translate documents, help make a contract with the clinic and open a medical visa. Other services of these agencies will be:

- To send a request to various clinics, clarify conditions of the examination required and choosing the optimal health facility (in time, level of services, credit standing of the patient, etc.);

- To help select one of the leading experts in the corresponding medical field and transfer all available medical records (medical statement, X-ray images, tests) to him;

- To make preliminary diagnosis and the plan of treatment and rehabilitation. Before traveling abroad the patient should have all the necessary information about all planned stages and methods of treatment;

- To provide information on the current level of risk associated with a particular type of treatment or surgery;

- To organize a special transportation, if needed;

- To provide accommodation either in a single or a double room ("luxury" accommodation is also possible), as well as accommodation with an accompanying person;

- To provide additional services after the patient returns home (eg, patient's communication with the doctor, sending necessary medicines by post).

Such a range of services, including legal protection, may not be always provided even by the law firm providing legal assistance while travelling. In this connection, medical tourism as a complex fusion of various areas, makes high demands for professionals who need to know the basic principles of general and international management 
and cross-cultural communication. They should understand the principles and functioning of tourism industry, organization of health systems in different countries, as well as insurance business and financing of health care, international law and legal aspects of rendering medical services, and finally, quality management of health services.

Most medical tourists from Russia traditionally go to Israel and Germany for treatment, which accounts for 45 and $20 \%$, respectively (Tourists go for medical treatment). This is partly due to the lack of a language barrier because of a large number of migrants from CIS countries. Currently, Turkey, Singapore, Switzerland, France and Eastern Europe are gaining popularity among Russian citizens as a destination of medical tourism. The most sought after are procedures in such areas, however, cardiac surgery, oncology, and treatment of chronic diseases require modern equipment. In Russia this type of tourism is provided by not more than 10 operators (In Moscow medical and non-barrier tourism is discussed again, 2011). The problem is that organization of these trips requires increased responsibility of the operators, and not all of them are ready to take it. The main flow of medical tourists go abroad for treatment on their own, finding the necessary clinic on the Internet, by the advice of their acquaintances. That is why the Internet remains the main advertising platform for both foreign and domestic medical institutions.

Speaking of attracting tourists to Russian medical institutions, Russia is on the list of countries that provide medical services to foreign patients, despite the fact that its health system does not fully fits the time. The level of many domestic experts, some public health centers with an international reputation, new private clinics is high enough for most modern examination and treatment in our country. However, there are at least two reasons, which are obstacles to treatment and rehabilitation of foreign citizens in Russia. Firstly, either a Russian clinic has an up-to-date medical equipment, but price for medical services is too high, or, secondly, a medical institution maybe famous for its doctors, but, as a rule, medical care and medical equipment leaves much to be desired.

\section{Discussions}

At the same time, development of medical tourism has led to several risk factors that entail problems associated with obtaining medical care abroad. These problems may occur, on the one hand, due to a wrong diagnosis, medical malpractice, cultural differences, and on the other hand, due to the difference in mentalities, religion, food habits, language barriers and so on. In addition, patients must trust their lives to someone they have never seen before in the country they have never been to (Risks and opportunities of medical tourism).

Focusing on other possible problems, it can be seen that in such countries as India, Malaysia, Costa Rica, various infectious diseases not existing in European countries and the USA are spread. Lack of strong immunity and resistance in a patient may lead to additional health problems, such as gastro- intestinal diseases (eg, hepatitis, amoebic dysentery, paratyphoid), and diseases transmitted by insects (eg, some species of mosquito can spread malaria, family mosquito carries the pathogen of onchoceriosis leading to blindness, fleas are a source of helminthiasis, encephalitis, tularemia) (Risks of medical tourism).

Problems may arise after the patient's arrival to the hospital. For example, it is known that long flights may not be recommended for those who suffer from cardiovascular and respiratory diseases. The flight can trigger thrombophlebitis, the risk of which increases after surgery

A weak point of medical tourism is also a low level of legal protection in case of a medical error or negligence. It must be remembered that legislation in the country of the patient's residence may differ significantly from the legislation of the country offering medical services. Today we can say that even medical centers with a worldwide reputation are not always able to provide service to the declared level. To minimize the risk of a poor service, the patient is offered to use services of an independent facilitator whom the patient could trust to present his medical interests at all stages of treatment, including diagnosis, the trip, as well as treatment and follow-up.

Another problem with medical tourism is that the travel agency, sending the patient abroad, is not responsible for the quality of medical services, for his health, but only mediates the trip and treatment. Although the role of intermediary organizations is important (contacts with foreign clinics, knowledge of health services market, their cost, etc,), the contract with the clinic is signed by the patient only.

In addition, there are cases when the patient is refused in travel and medical care. This is due to the patient's incurable disease at a terminal stage when no treatment will help, and the trip itself will only worsen the situation, because a flight is stressful for the patient. Also, trips are not organized for patients with mental disorders and addictions, as they should be treated in the familiar language and social environment. 


\section{Conclusions}

According to experts for the progressive development of medical tourism and successful promotion tours, medical tourism organizations should undertake the following:

- To reduce the price of the tour as much as possible, for example, by engaging skilled medical personnel for primary and more detailed diagnosis, which reduces the time and cost of treatment abroad;

- To create package tourist products by initiating direct contacts with customers. Attracting medical personnel is necessary at the stage of the tour planning to specify the clinic profile, contraindications for this type of treatment, as there is a large variety of the clinics of the similar profile and to choose the most suitable for the client a qualified professional advice is required;

- To reduce the number of intermediaries between the client and the clinic, which will lead to less distortion of information and may allow travel agents to negotiate discounts, or a fixed cost for each patient sent to the clinic, this in it's turn will allow travel agents to align the cost of medical tours;

- To create a wider advertising of this type of tourism with commentaries by the people who have been treated in various clinics. This is very important for the tourism industry organizations and their clients, because it is this way - by word of mouth information about treatment abroad spreads. One should establish and maintain contacts with clients who have returned from a trip to be able to advertise this or that foreign clinic from their personal experience;

- To stir interest in primary care physicians (out-patient clinics),to provide them with accurate and detailed information on foreign hospitals, their capabilities and methods of treatment, so that they in turn could recommend certain clinics for their patients, which is widely practiced abroad. Such well-established contacts with specialists will be able to refer to their opinion about a particular clinic or method of treatment (Development and promotion of medical tours on the market of Krasnodar Kray).

In conclusion, the following can be stated: Medical tourism is a fast growing area of economy, both in developed countries and in emerging economies. As for today's Russia, medical tourism is not in great demand among patients due to a number of reasons, the main being economical ones. However, its development in our country is promising.

\section{References}

ASPECT. International Medical Tourism. International Health Care Center. (n. d.). Retrieved August 25, 2014, from http://medaspect.com.ua/lechenie-v-indii/apollo-kliniki

Development and promotion of medical tours on the market of Krasnodar Kray. (n. d.). Retrieved August 28, 2014, from http://www.5erochka.ru/5erochka/catalog/detail.php?ID=2153

Electronic European encyclopedia. The state of Israel. Health care system. (n. d.). Retrieved August 28, 2014, from http://www.eleven.co.il/article/11738

Health care in the USA. (2014, March 26). Retrieved August 26, 2014, from http://ru.wikipedia.org/wiki

In Moscow medical and non-barrier tourism is discussed again. (2011, November 14). Retrieved August 27, 2014, from http://www.atorus.ru/news/press-centre/new/13782.html

Lebedeva, L. F. (2011). Economic Value of B. Obama's Social Policy. Russia and America in the XXI century. Retrieved August 28, 2014, from http://www.rusus.ru/print.php?id=276

Medical information net. (n. d.). Retrieved August 26, 2014, from http://www.medicinform.net/lechen/zdrav.htm

Medical tourism is beneficial to everybody. (2011, March 11). Retrieved August 25, 2014, from $\mathrm{http}: / / w w w . v e c h n a y a m o l o d o s t . r u / p a g e s / m e d t u r v y v s 23 . h t m l$

Medical tourism. (n. d.). Retrieved August 28, 2014, from http://www.intmedtourism.com/ru/medical-tourism

Medical tourism. Made in India. (n. d.). Retrieved August 25, 2014, from http://www.worlds.ru/asia/india/ history-medicinskijj_turizm_sdelano_v_indii.shtml

Medical tourism: where can you go? (2010, December 8). Retrieved August 28, 2014, from http://www.newsland.ru/news/detail/id/597635

Medical treatment in Germany. (n. d.). Retrieved August 25, 2014, from http://www.germed.ru

Risks and opportunities of medical tourism. (n. d.). Retrieved August 26, 2014, from http://www.abctours.ru/ world/medicina-v-germanii.php 
Risks of medical tourism. (n. d.). Retrieved August 27, 2014, from http://ru.hicow.com/983143.html

Shchekin, G., \& Antonova, T. (2013). Comparative analysis of medical tourism services in Russia and western countries on basis of oncological diseases. Humanities and social-economic research (pp. 85-88).

Tourists go for medical treatment. (2011, December 2). Retrieved August 25, 2014, from http://www.agregator. pro/turistyi_edut_lechitsya.13664.html

Tourists go for medical treatment. (n. d.). Retrieved August 29, 2014, from http://vladmedicina.ru/news/russia// 2011-12-03-turisty-edut.htm

Traveling to India. Medical tourism. (n. d.). Retrieved August 26, 2014, from http://travel-india.ucoz.com/index/ medicinskij_turizm/0-194

Treatment in Italy. (n. d.). Retrieved August 25, 2014, from http://medvoyage.info/countries/italy.html

\section{Copyrights}

Copyright for this article is retained by the author(s), with first publication rights granted to the journal.

This is an open-access article distributed under the terms and conditions of the Creative Commons Attribution license (http://creativecommons.org/licenses/by/3.0/). 